\title{
Composition of the Microbiomes from Spinach Seeds Infested or Noninfested with Peronospora effusa or Verticillium dahliae
}

\author{
Shyam L. Kandel, ${ }^{\dagger}$ Peter M. Henry, Polly H. Goldman, Beiquan Mou, and Steven J. Klosterman ${ }^{\dagger}$ \\ United States Department of Agriculture-Agricultural Research Service, Crop Improvement and Protection Research Unit, Salinas, CA 93905, U.S.A.
}

Accepted for publication 3 October 2021.

\begin{tabular}{|c|c|}
\hline $\begin{array}{l}\text { The worldwide distribution of plant seeds can disseminate } \\
\text { beneficial and plant-pathogenic microorganisms. This phenome- } \\
\text { non is of particular concern where seed production is geographi- } \\
\text { cally isolated from crop production, as is the case with spinach in } \\
\text { the United States. We aimed to characterize the structure and } \\
\text { function of spinach seed microbiomes in commercial spinach seed } \\
\text { lots originating from Europe and New Zealand. The seed lots we } \\
\text { analyzed were infested with Peronospora effusa and Verticillium } \\
\text { dahliae, only infested with } V \text {. dahliae, or not infested with either of } \\
\text { these pathogens. The microbial taxonomic composition and gene } \\
\text { function (assessed by gene ontology [GO] terms) of spinach } \\
\text { seeds were highly influenced by geographic origin and the status } \\
\text { of pathogen infestation. Through taxonomic profiling, we found } \\
\text { that potentially plant-beneficial bacterial genera such as Pseudo- } \\
\text { monas and Pantoea were the most abundant taxa both in infested }\end{array}$ & $\begin{array}{l}\text { and noninfested seeds, and Stenotrophomonas was observed in } \\
\text { seed lots infested with } P \text {. effusa and } V \text {. dahliae. Many potential } \\
\text { plant pathogens that are not known to be associated with spinach } \\
\text { seed were also discovered by metagenomic analysis, including } \\
\text { Sclerotinia sclerotiorum, Botrytis cinerea, Bipolaris sorokiniana, } \\
\text { Fusarium pseudograminearum, Alternaria brassicae, A. solani, } \\
\text { Parastagonospora nodorum, and Pyrenophora teres f. teres. Our } \\
\text { analysis of the function of prokaryotic genes in de novo assembled } \\
\text { metagenomes revealed distinct GO terms associated with the } \\
\text { geographic origin of seed lots. This work provides an important } \\
\text { first step toward identifying spinach seedborne microorganisms } \\
\text { that could be utilized to improve plant health and plant pathogens } \\
\text { that could be inadvertently carried to new locations. } \\
\text { Keywords: spinach, metagenomics, microbiome, plant pathology }\end{array}$ \\
\hline
\end{tabular}

Plant microbiomes are considered an integral part of plant health that can confer tolerance to stress and influence overall growth and

†Corresponding authors: S. J. Klosterman; Steve.Klosterman@usda.gov, and S. L. Kandel; Shyam.Kandel@usda.gov

Current address of S. L. Kandel: USDA-ARS Sugarbeet and Potato Research Unit, Fargo, ND 58102, U.S.A.

Mention of trade names or commercial products in this publication is solely for the purpose of providing specific information and does not imply recommendation or endorsement by the United States Department of Agriculture (USDA). USDA is an equal opportunity provider and employer.

Funding: This research was funded, in part, by grants from the United States Department of Agriculture (USDA) Agricultural Marketing Service Specialty Crop Multistate Program (award number 16SCCMAR0001), USDA National Institute of Food and Agriculture (NIFA) Agriculture and Food Research Initiative (award number 201668004-24931), and USDA-NIFA Specialty Crop Research Initiative (award numbers 2015-51181-24283 and 2017-51181-26830).

*The $\boldsymbol{e}$-Xtra logo stands for "electronic extra" and indicates that two supplementary tables and four supplementary figures are published online.

The author(s) declare no conflict of interest.

This article is in the public domain and not copyrightable. It may be freely reprinted with customary crediting of the source. The American Phytopathological Society, 2022. development (Fitzpatrick et al. 2020; Singh et al. 2020; Trivedi et al. 2020). Plants can recruit microbial communities from their initial reproductive tissues such as seeds or rhizomes, as well as from their environment (Hassani et al. 2019; Toju et al. 2018; Turner et al. 2013). On seeds, microorganisms can reside in the embryo or superficially embedded on or in the seed coat and pericarp. Seedborne microbiota can become founders of the new plant's microbial community and have substantial impacts on plant health outcomes (Barret et al. 2016; Nelson 2018; Torres-Cortés et al. 2018). For example, it has long been known that some plant pathogens are seedborne and benefit from the attendant opportunity for early plant colonization (du Toit et al. 2005; Hernandez-Perez and du Toit 2006). However, plant mutualistic or commensal organisms can also be seedborne, and much less is known about their occurrence and impacts on plant health (Berg and Raaijmakers 2018; Shade et al. 2017; Shahzad et al. 2018).

For many crops, there is geographic separation between seed and crop production. For example, spinach requires long photoperiods to initiate flowering and arid conditions during seed maturation and harvesting. Because of these highly specific requirements, nearly all commercially available spinach seed is produced in only a few regions: the Pacific Northwest region of the United States, Denmark, The Netherlands, and New Zealand. By contrast, nearly $65 \%$ of U.S. fresh-market spinach is grown in the mild climates of coastal California where production can occur almost year-round (USDA-NASS 
2019). The requisite movement of seeds unintentionally serves as a portal for widespread dissemination of seedborne microbiota.

In spinach seed, a mature ovule is enclosed by a thick pericarp, which may provide habitat for microorganisms that can then be disseminated along with the seeds. Plant pathogens causing downy mildew (Peronospora effusa) in spinach and Verticillium wilt (Verticillium dahliae) in lettuce and strawberry are carried on infested spinach seeds (Carroll et al. 2017; Duressa et al. 2012; Inaba et al. 1983; Kunjeti et al. 2016; Maruthachalam et al. 2013; Olesen et al. 2014). Downy mildew causes severe losses, especially in organic spinach production, for which there are no effective approved fungicides. Viable oospores of $P$. effusa have been reported in commercial spinach seed lots that may serve as the primary inoculum in spinach fields. As a product of sexual reproduction, these oospores may also facilitate increased genetic diversity in the pathogen population (Choudhury et al. 2016; Kandel et al. 2019; Kunjeti et al. 2016). Likewise, Verticillium wilt is one of the major concerns for lettuce and strawberry growers in California (Carroll et al. 2017; Klosterman et al. 2009). Previous studies have clearly demonstrated that $V$. dahliae from infested spinach seeds can infect subsequent lettuce crops and release millions of microsclerotia (long-term survival structures of $V$. dahliae) in soil (Maruthachalam et al. 2013; Short et al. 2015). Furthermore, leaf spot and anthracnose pathogens in spinach such as Stemphylium spp., Cladosporium variabile, Alternaria spp., Colletotrichum dematium, and other plant pathogens, including Botrytis and Fusarium spp., can be carried on infested spinach seeds (Feng et al. 2014; Hernandez-Perez and du Toit 2006). In recent years, leaf spots in spinach crops have been reported with increasing frequency in the United States (Liu et al. 2020, 2021).

Exacerbating the potential consequences of seed trafficking is the increasing popularity of baby-leaf spinach, which has necessitated a great expansion in the volume of imported seeds. Baby-leaf spinach is planted at a much higher density than large-leaf spinach and, therefore, the seed requirements are greatly increased (to nearly 10 million seeds/ha) (Kandel et al. 2019; Koike et al. 2011). In the United States, up to $50 \%$ of the spinach seed demand is fulfilled from overseas imports from Denmark, The Netherlands, and New Zealand (Foss and Jones 2000; USDA-FAS 2020). Very little is known about the taxonomic identity and composition of the spinach seed microbiota that is imported in increasing volumes to various growing regions.

Given this significance, it is critical to gain a more in-depth understanding of the microorganisms associated with seed imported into spinach crop production regions from spinach seed-producing regions. The main objective of this study was to characterize seedassociated microorganisms in six spinach seed samples originating from Northern Europe and New Zealand. To achieve this objective, we used shotgun metagenomics to probe taxonomic and gene function diversity. Our improved understanding of the spinach seed microbiome may lead to new methods for improving plant health through the manipulation of seedborne microbiota.

\section{MATERIALS AND METHODS}

Spinach seed sources and determination of $P$. effusa and $V$. dahliae infestations. Samples of six commercial spinach seed lots from Europe and New Zealand were obtained for this study (Table 1). We used previously described methodology to assess seed lots for P. effusa and V. dahliae infestations (Kabir et al. 2004; Kunjeti et al. 2016). For $P$. effusa, 1,000 seeds from individual seed lots were washed for 10 min by vigorous agitation on a MoBio VortexGenie2 (Scientific Industries, Inc., Bohemia, NY, U.S.A.). The dislodged seed materials were collected by centrifugation for $5 \mathrm{~min}$ at
$5,000 \times g$ and an aliquot of the seed sediment was observed under the microscope. Intact oospores were counted under the microscope and reported as the number of oospores in each seed lot (Kunjeti et al. 2016). To quantify $V$. dahliae infestation, spinach seeds were placed on NP10 (a semiselective medium), incubated in a highhumidity chamber, and observed for colonies with morphology that is characteristic of $V$. dahliae (Kabir et al. 2004). Three replicates from each seed lot were analyzed by both the seed wash-off method (for $P$. effusa) and plating on semiselective media (for $V$. dahliae).

Seed sample preparation and DNA extraction. We performed three replicate DNA extractions on each seed lot. Seed debris were collected from washing off the seed pericarp and used for DNA extractions. For each extraction, 1,000 seeds were placed in $20 \mathrm{ml}$ of sterile $10 \mathrm{mM}$ phosphate buffer at $4^{\circ} \mathrm{C}(\mathrm{pH}$ 7.0), vortexed for $10 \mathrm{~min}$ at $4^{\circ} \mathrm{C}$ on a Vortex-Genie2, and shaken at $200 \mathrm{rpm}$ and $4^{\circ} \mathrm{C}$ for $10 \mathrm{~min}$. The supernatant was removed and this, plus an additional rinse of $20 \mathrm{ml}$ of $4^{\circ} \mathrm{C}$ buffer, was centrifuged for $10 \mathrm{~min}$ at $7,000 \times g$ at $10^{\circ} \mathrm{C}$ using a Sorval RC-5B centrifuge (Thermo Fisher Scientific, Santa Clara, CA, U.S.A.). DNA was isolated from the pelleted seed debris with the G-Biosciences OmniPrep kit (G-Biosciences, St. Louis, MO, U.S.A.) following the manufacturer's recommended procedure. The extracted DNA was purified using AMPure magnetic beads (Beckman Coulter, Pasadena, CA, U.S.A.), assessed for residual contamination by quantifying the ratios of absorbance at 260/230 $\mathrm{nm}$, and 260/280 nm on a NanoDrop 8000 (Thermo Fisher Scientific, Wilmington, DE, U.S.A.), and quantified by Qubit version 3 fluorometry (Thermo Fisher Scientific, Wilmington, DE, U.S.A.). To check for DNA shearing that could have occurred during extraction, we ran 50 to $500 \mathrm{ng}$ of DNA with a $\lambda$ HindIII marker on a $1 \%$ agarose gel for 30 to $45 \mathrm{~min}$. Following quality checks, samples were stored at $-80^{\circ} \mathrm{C}$ in $50 \mu \mathrm{l}$ of Tris-EDTA buffer (10 mM Tris base and $1 \mathrm{mM}$ EDTA, $\mathrm{pH}$ 8.0). Centrillion Biosciences (Palo Alto, CA, U.S.A.) prepared 1 library per DNA sample (i.e., 3 libraries per seed lot; $n=18$ total) and sequenced them on an Illumina HiSeq2500 with V3 chemistry, $2 \times 150$ paired-end read lengths, and library pooling to achieve 50 million reads per sample. Raw sequence data were delivered as fastq files.

Read preprocessing and quality filtering. All metagenomic reads from the HiSeq 2500 System were imported into the CLC Microbial Genomics Module (Qiagen, Aarhus, Denmark) to perform downstream analysis. In the CLC Microbial Genomics Module, the default setting of the "Data QC and Clean Host DNA" workflow was used to trim adapter sequences and remove host (i.e., spinach) genome sequences (https://github.com/USDA-ARS-GBRU/Spinach_ Peffusa) (Kandel et al. 2020). Reads with a minimum quality score of 0.01 (equivalent to Phred quality score of 20) or a posttrimming length of $15 \mathrm{bp}$ or less were filtered out of the dataset.

Taxonomic profiling and relative abundance analysis. We created a custom reference database of whole fungal and bacterial genomes for our analyses. All 16S and internal transcribed spacer (ITS) sequences from the SILVA ribosomal RNA (rRNA) (https:// mothur.org/wiki/silva_reference_files/) and UNITE ITS (https:// plutof.ut.ee/\#/doi/10.15156/BIO/786334) (Schloss et al. 2009; UNITE Community 2019) databases were searched against whole-genome assemblies in the GenBank data repository (at the NCBI). Using the database builder tool in CLC Genomics, we compiled all wholegenome assemblies with matching sequences in the SILVA rRNA (bacterial) and UNITE (fungal) databases.

For taxonomic profiling, each quality-filtered input read $>50 \mathrm{bp}$ in length from every sample was mapped to this custom reference database of bacterial and fungal whole-genome sequences. We used the default read mapping parameters from CLC Genomics, including match score $=1$, mismatch $\operatorname{cost}=2$, and autodetection of paired 
distances. The latter parameter ensured that both reads in a read pair were utilized for determining a matching reference sequence.

After read mapping, the taxonomic profiling tool was utilized to quantify the abundance of reads corresponding to each taxon and report these abundances in a table that included taxonomic information and a coverage estimate (CLC Microbial Genomics Module; Qiagen). Read abundance tables were used to summarize $\beta$ (between-sample) and $\alpha$ (within-sample) diversities, perform differential abundance analysis (minimum absolute fold change $=2$ and false discovery rate $P$ value $\leq 0.05$ ), and create heatmaps that were hierarchically clustered by the relative abundance of bacterial and fungal species. We used 'Differential Abundance Analysis' and 'Create Heat Map for Abundance table' tools in CLC Genomics to perform these analyses.

Metagenome assembly and functionally profiling predicted gene sequences. Metagenomes assembled from shotgun-sequenced samples can add depth to microbiome analyses by enabling the analysis of gene functions (Zhong et al. 2021). We assembled shotgun-sequenced metagenomic reads into contigs with the 'de novo metagenome' tool of CLC Genomics with a minimum contig length parameter set to $500 \mathrm{bp}$.

The resulting contigs were further annotated with coding sequences (CDS) using the 'Find Prokaryotic Genes' tool in the CLC Genomics. This tool prepared a gene prediction model by assessing the GC content, conserved sequences related to ribosomal binding sites and start and stop codon uses, and predicted coding sequences in contigs. From this analysis, contigs with CDS annotations were received. Whole contigs containing CDS annotations were used to annotate with Pfam (protein families) and GO (gene ontology) terms using protein databases UniProt Reference Clusters, UniRef50, and GO database (Prokaryotic GO subset), respectively. The protein and GO databases were directly downloaded from CLC Genomics Workbench and used in our analysis. Finally, functional analysis identified abundance values corresponding to Pfam domains and GO terms in each metagenome assembly. GO terms were summarized using heatmaps. The GO terms abundance matrix was normalized and visualized using heatmaps in R (R Core Team 2020). The R package 'vegetarian' was used for normalization (Charney and Record 2012). A set analysis was performed to identify unique and shared GO terms across seed samples and visualized with UpSet plot using $\mathrm{R}$ package UpSetR (Lex et al. 2014). GO terms related to biological process, molecular function, and cellular component were summarized and visualized in a scatter plot using online tool REVIGO (Supek et al. 2011).

With the 'bin pangenomes by taxonomy' tool in CLC Genomics, we assigned contigs into bins according to taxonomic relatedness at the species level. The sum of all contigs assigned to a taxon are considered the sample-specific pan-genome for that taxon. We assigned taxonomic designation to each pan-genome using our custom database of whole microbial genomes. For taxonomic assignment we used the following parameters: minimum contig length $=500 \mathrm{bp}$, contig purity maximum level $=$ species, and minimum purity $=0.9$.

\section{RESULTS}

Description of seed samples and shotgun sequencing dataset. In this study, we analyzed the microbiomes of six commercial spinach seed lots imported to the United States from Europe and New Zealand with different levels of infestation with $P$. effusa and $V$. dahliae (Table 1). Purified DNA samples $(n=6)$ recovered from the seed pericarp were subjected to highthroughput 150-bp paired-end Illumina Hiseq 2500 sequencing. Nearly 1.3 billion sequences were received and approximately 1.1 billion sequences remained after trimming adaptors and removing low-quality, short ( $<50 \mathrm{bp})$, ambiguous, and host genome sequences. On average, we obtained $7.4 \times 10^{7}$ reads per library ( $n=18$ libraries) for taxonomic and functional profiling (Supplementary Table S1).

Taxonomic profiling. Taxonomic profiling by mapping reads to a database of reference genomes was performed to understand the composition and diversity of microbial communities in the spinach seed samples. In total, 732 bacterial and 89 fungal species were identified across all seed samples. The most abundant bacterial families were Pseudomonadaceae, Erwiniaceae, Xanthomonadaceae, and Microbacteriaceae (Fig. 1A). Pseudomonas and Pantoea were the most common bacterial genera in all seed samples (Fig. 1B). The most abundant fungal families were Pleosporaceae, Sclerotiniaceae, Plectosphaerellaceae, Phaeosphaeriaceae, and Nectriaceae (Fig. 2A). The most abundant fungal genera were Botrytis, Alternaria, and Verticillium among all seed samples (Fig. 2B). The highest relative abundance of Verticillium was found in seed lot number 2 (Fig. 2B), from which we observed the highest levels of pathogen infestation in plate assays (Table 1). Furthermore, pangenomes of the most abundant bacterial species, including Pseudomonas syringae, P. fluorescens, P. poae, and Pantoea agglomerant, and fungal species such as Botrytis cinerea, Alternaria brassicae, A. solani, and $V$. dahliae, were identified by generating pangenomes by taxonomy. In European seed lots, the possible plant pathogens included Fusarium oxysporum, F. pseudograminearum, Bipolaris sorokiniana, and Sclerotinia sclerotiorum whereas, in the New

TABLE 1

Geographical origin and harvest year of spinach seed lots used in this study, along with the status of seedborne plant pathogens Verticillium dahliae and Peronospora effusa

\begin{tabular}{|c|c|c|c|c|c|}
\hline Seed lot & Geographic origin & Origin year & $\begin{array}{c}\text { V. dahliae } \\
\text { infestation (\% seeds) }\end{array}$ & $\begin{array}{l}P \text {. effusa infestation, (oospores } \\
\text { per } 1,000 \text { seeds) }\end{array}$ & $\begin{array}{c}\text { Treatment } \\
\text { designation }\end{array}$ \\
\hline 1 & New Zealand & 2017 & $4(0.7)$ & $46(2.1)$ & In. \\
\hline 3 & Europe & 2016 & $2(0.01)$ & $34(1.2)$ & In. \\
\hline 4 & Europe & 2018 & 0 & 0 & Non-In. \\
\hline
\end{tabular}


Zealand seed lots, we identified Valsa mali and $F$. venenatum as potential plant pathogens.

We also mapped all metagenomic reads to SILVA $16 \mathrm{~S}$ v132 and UNITE fungal ITS v7.2 databases (Schloss et al. 2009; UNITE
Community 2019), recovered mapped reads, and performed the operational taxonomic unit clustering using the default parameters of amplicon-based analysis tool in the CLC Microbial Genomics Module. Taxonomic diversity identified in all seed lots through $16 \mathrm{~S}$

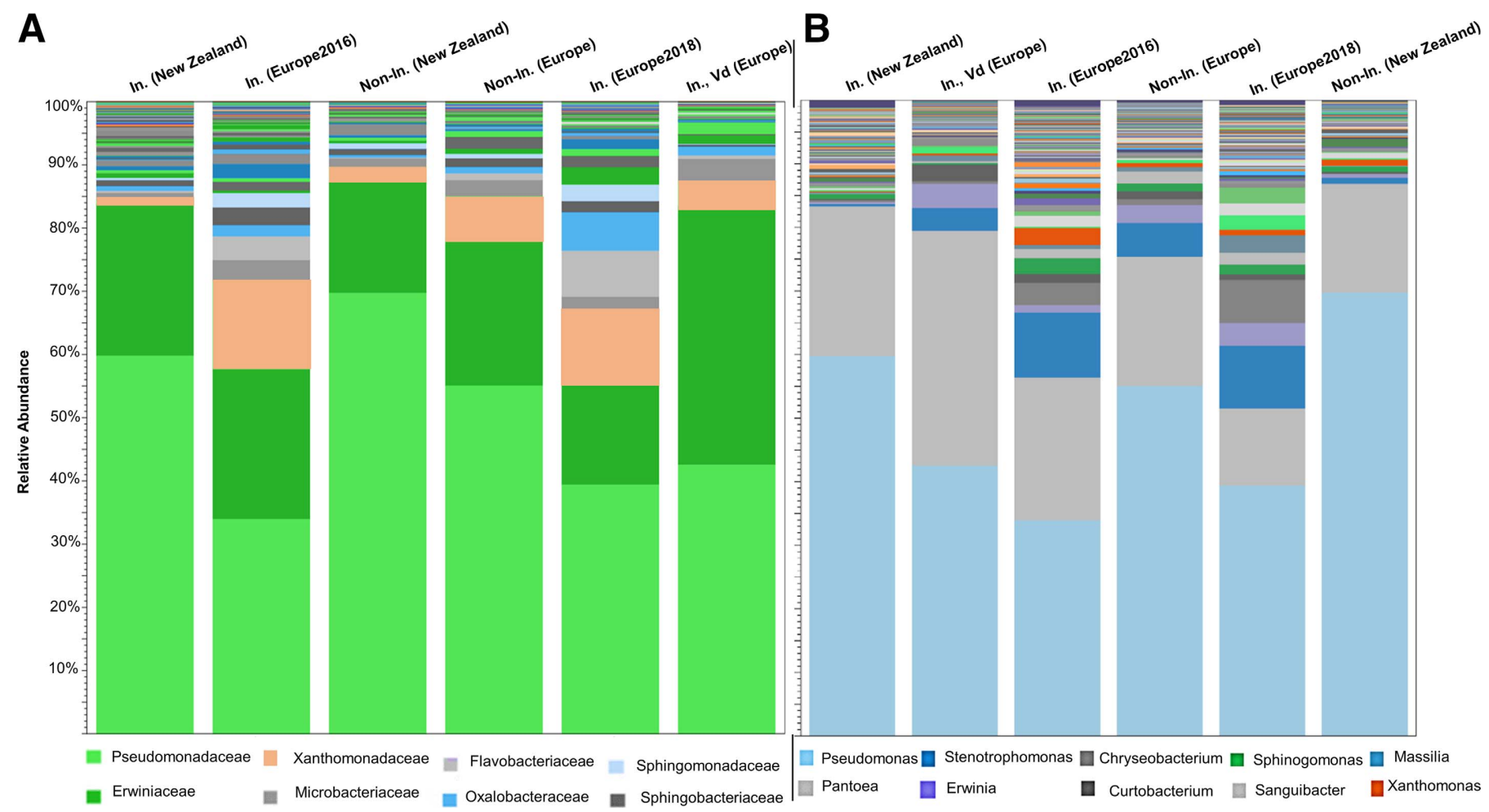

Fig. 1. Taxonomic profiling of bacterial communities across all seed samples from Europe and New Zealand: A, family and B, genus. Here, color matrix indicates the designated taxonomic unit. In. = infested with Peronospora effusa and Verticillium dahliae, In. Vd = infested only with V. dahliae, and Non-In. = not infested with either pathogen.

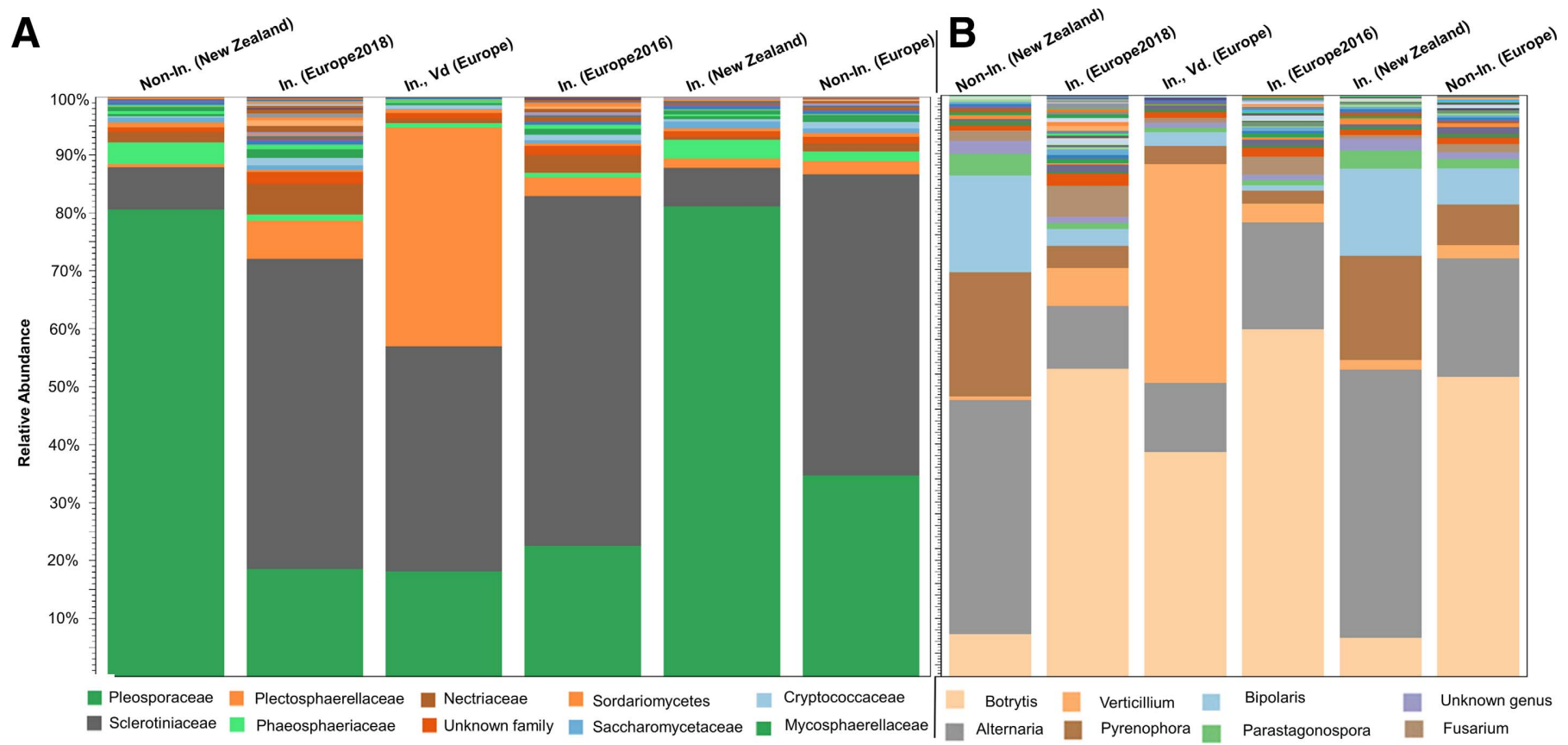

Fig. 2. Taxonomic profiling of fungal communities across all seed samples from Europe and New Zealand: A, family and B, genus. Here, color matrix indicates the designated taxonomic unit. In. = infested with Peronospora effusa and Verticillium dahliae, In. Vd = infested only with V. dahliae, and Non-In. = not infested with either pathogen. 
or ITS rRNA amplicon-based analysis revealed some agreement with taxonomic profiling using the whole-genome database (Supplementary Figs. S1 and S2).

Between-sample $\boldsymbol{\beta}$ diversity: Microbial community structure. $\beta$ Diversity was assessed by a principal coordinate analysis (using the Bray-Curtis dissimilarity metric) from species-level taxonomic assignments in each sample (Condit et al. 2002). Regardless of whether either Verticillium dahliae or Peronospora effusa were present, both fungal and bacterial communities from the New Zealand samples clustered distinctly from European samples (Fig. 3). For the bacterial community, samples infested with $P$. effusa and $V$. dahliae were clustered together, whereas they were clustered separately for the fungal community.

Within sample $\alpha$ diversity (bacteria): Species richness and diversity index. $\alpha$ Diversity refers to the taxonomic diversity in a sample and can be estimated by multiple metrics, including species richness (i.e., the number of species within the sample), or Simpson's index (a metric that summarizes both number and abundance of species). Bacterial species richness and diversity (as measured by Simpson's index) were significantly different among seed lots (Fig. 4). However, no significant difference ( $\alpha=0.05$; Kruskal-Wallis H test) was observed in fungal diversity among seed samples. Overall, bacterial species richness was higher in infested seed samples. The highest and lowest species richness was observed in infested or noninfested seed lots from Europe and New Zealand, respectively (Fig. 4A). The Simpson's index indicated that higher bacterial diversity was associated with infested seed lots from both New Zealand and Europe as compared with noninfested seed samples from either location.

Differential abundance analysis and presence or absence variation. We performed differential abundance analysis to identify bacterial and fungal species associated with the geographic origin or $P$. effusa and $V$. dahliae infestation of seed lots. Interestingly, the differential abundance of bacterial and fungal species was often correlated with geographic origin; those occurring at a higher number in New Zealand samples were less abundant in European samples and vice versa (Figs. 5 and 6). For example, Pseudomonas fluorescens was abundant in both infested and noninfested New Zealand seed lots but not in European seed lots (Fig. 5). By contrast, Duganella zoogloeoides, Halomonas zhanjiangensis, Curtobacterium sp., and Enterobacter sp. were more abundant in European seed lots (Fig. 5). Among fungal species, isolates of $V$. dahliae and $F$. pseudograminearum were far more abundant in infested seed lots from Europe, whereas B. sorokiniana, Parastagonospora nodorum, and Pyrenophora teres f. teres were more common among New Zealand seed samples (Fig. 6).

In addition to comparing differential abundance, we identified taxa with presence or absence variation between seed lots. Interestingly, we observed the greatest presence or absence variation of bacterial species between samples that differed in both geographic origin and pathogen infestation; the noninfested (Europe) and infested (New Zealand) group differed by 171 taxa. In contrast, only 67 bacterial species had presence or absence variation between the noninfested (Europe) and infested (Europe) group (Supplementary Fig. S3). In total, 37 fungal species had presence or absence variation between the infested European and the noninfested New Zealand seed lots (Supplementary Fig. S4).

Identification of commonly abundant microbiomes and de novo genome assembly. In this study, we refer to "commonly abundant microbiomes" as the bacterial and fungal communities that are present in all seed samples (Supplementary Table S2). In all, 22 bacterial and 5 fungal species were present as the commonly abundant microbiomes of the spinach seed lots analyzed for this study. The core bacterial community was almost entirely composed of Pantoea spp. and Pseudomonas spp., whereas A. brassicae, A. solani, Pyrenophora teres, B. sorokiniana, and Botrytis cinerea B05.10 formed the core fungal community.

The commonly abundant microbiota were identified among the samples, which enabled de novo genome assembly of these taxa. Using the 'bin pangenomes by taxonomy' tool, in total, 15,316 contigs were generated and assigned to 106 bins corresponding to species-level taxonomy. Among these bins, we were able to identify the core bacterial species Pseudomonas syringae, P. fluorescens, $P$. poae, and Pantoea agglomerans and the core fungal species $B$. cinerea, A. brassicae, A. solani, and $V$. dahliae. Given the
A

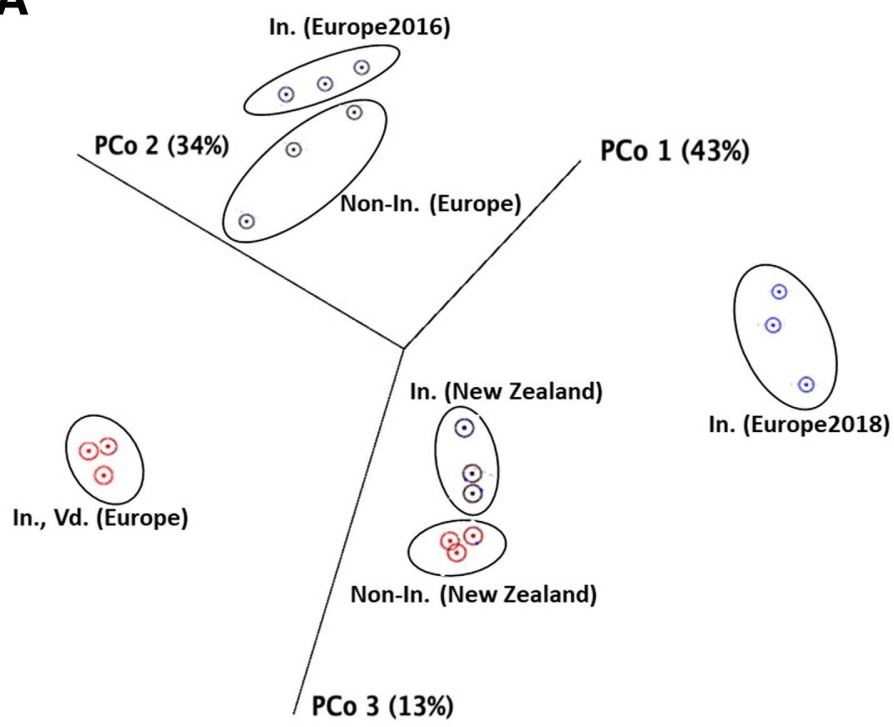

B

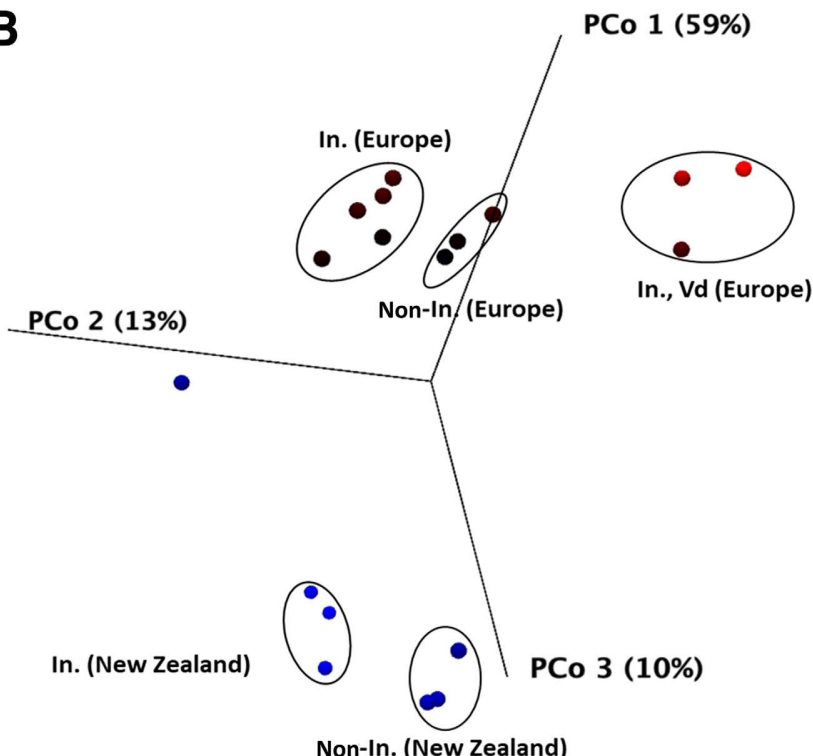

Fig. 3. Microbial community structure comparison from six spinach seed lots $(n=6)$. Principal coordinate (PCo) analysis, between-sample $\beta$ diversity (Bray Curtis): A, Fungi and B, Bacteria. Red color indicates higher abundance and blue color indicates smaller abundance of microbial community. In. = infested with Peronospora effusa and Verticillium dahliae, In. Vd $=$ infested only with $V$. dahliae, and Non-In. $=$ not infested with either pathogen. 
congruence between reference-guided and de novo analyses, we can say with high confidence that these are the core microbiota of these spinach seed lots.

Functional profiling. In total, $2 \times 10^{8}$ Pfam domains and $1.5 \times$ $10^{9} \mathrm{GO}$ terms were matched to the UniRef50 protein database and the GO database (Prokaryotic GO subset), respectively. Nearly 3,500 GO terms were identified in each seed lot, while approximately 2,500 GO terms were shared across seed lots. GO terms that occurred in a higher abundance in New Zealand samples occurred less frequently in European samples, and vice versa (Fig. 7). Furthermore, pathogen infestation influenced the occurrence of GO terms among samples.

The unique GO terms in each seed sample or shared among seed samples were plotted using the UpSet plot (Fig. 8). Here, we identified 19 and 81 'core' GO terms in New Zealand and European seed samples, respectively. The core GO terms were summarized using REVIGO. The major core GO terms related to biological process abundant in metagenomes of New Zealand seed microbiomes were "response to endogenous stimulus", "glycosylceramide catabolic process", and "response to hormone" (Fig. 9A). In the metagenomes of European seed microbiomes, "reproduction", "cell killing", "response to antibiotic", and "killing of cells of other organism" were the major GO terms related to biological processes (Fig. 9B).

\section{DISCUSSION}

Spinach seed is planted at very high densities of nearly 10 million spinach seeds/ha for baby leaf production, and there has been increased demand for fresh spinach since the mid-1990s (Atallah et al. 2010; Koike et al. 2011). Most of the spinach seed demand in the United States is fulfilled from importation, mainly from Denmark, The Netherlands, and New Zealand (USDA-FAS 2020). Spinach seeds may harbor pathogens that can cause disease on spinach or crops grown in rotation with spinach (Feng et al. 2014; Kandel et al. 2019). For example, V. dahliae found on spinach seed can infect subsequent lettuce crops grown in the same soil (Short et al. 2015). Therefore, assessing the microbial communities that may be present on commercial seed spinach lots is increasingly important to decipher the range of pathogenic microbes present and microbes that may potentially be used in strategies to predict or control harmful plant pathogens. In this study, we examined the microbiome diversity in six spinach seed lots from two different continents. The results highlight differences between the bacterial and fungal communities between these seed lots.

Seed-associated microorganisms serve as founder populations to the plant microbiome and contribute to seedling establishment (Berg and Raaijmakers 2018; Nelson 2018). The selective recruitment and transmission of plant endophytes through seeds over generations has been documented (Bergna et al. 2018). The pericarpal surface of spinach seed is uneven and relatively thick, which probably provides a favorable environment for microbes to colonize and reside. To date, the composition and magnitude of microbial community residing on spinach seed lots was largely unknown. By using principal coordinate analysis (Bray-Curtis), we summarized the overall diversity of spinach seed microbiomes (Fig. 3). The microbial diversity was distinct in European versus New Zealand seed lots and varied with the status of Peronospora effusa and $V$. dahliae infestation. The overall bacterial species richness was higher in infested seed samples. In response to the $P$. effusa and $V$. dahliae infection, spinach plants may recruit diverse bacterial species as a defensive strategy to induce host immunity, possibly from root-associated bacteria, as has been reported elsewhere (Liu et al. 2017; Palmieri et al. 2020; Pascale et al. 2020).

The geographical origin of seed lots and presence of $V$. dahliae or $P$. effusa inoculum influenced the microbiome assemblage of spinach seeds. The extent and the types of bacterial and fungal species in
A

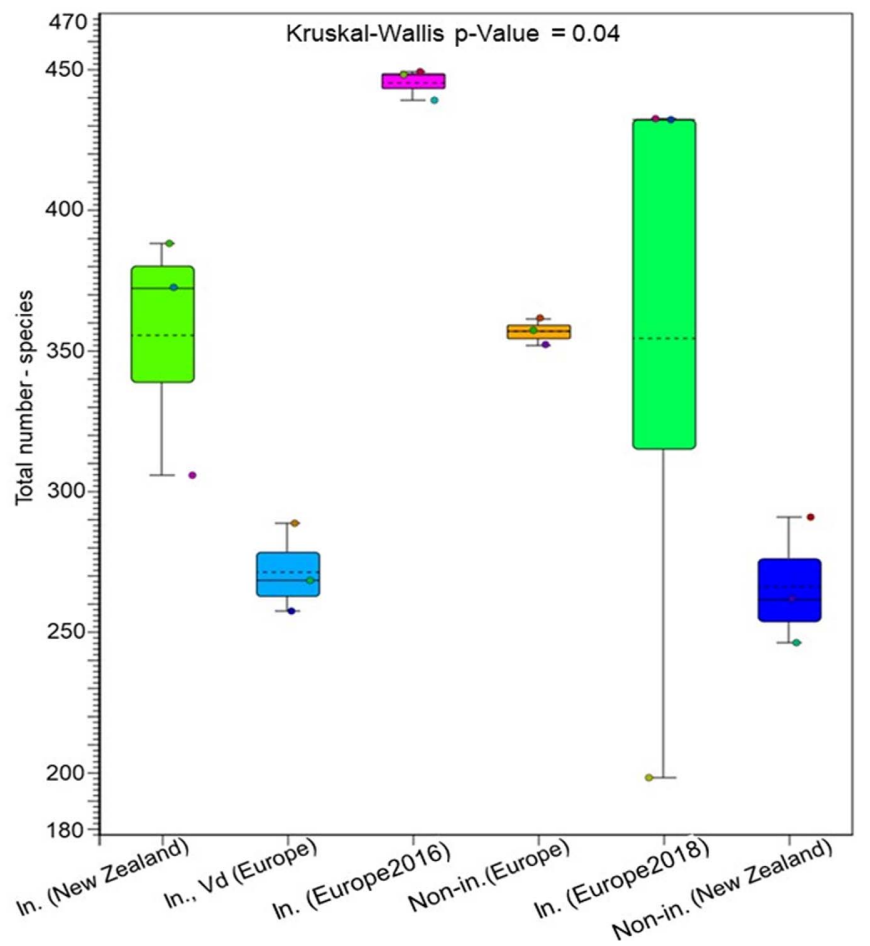

B

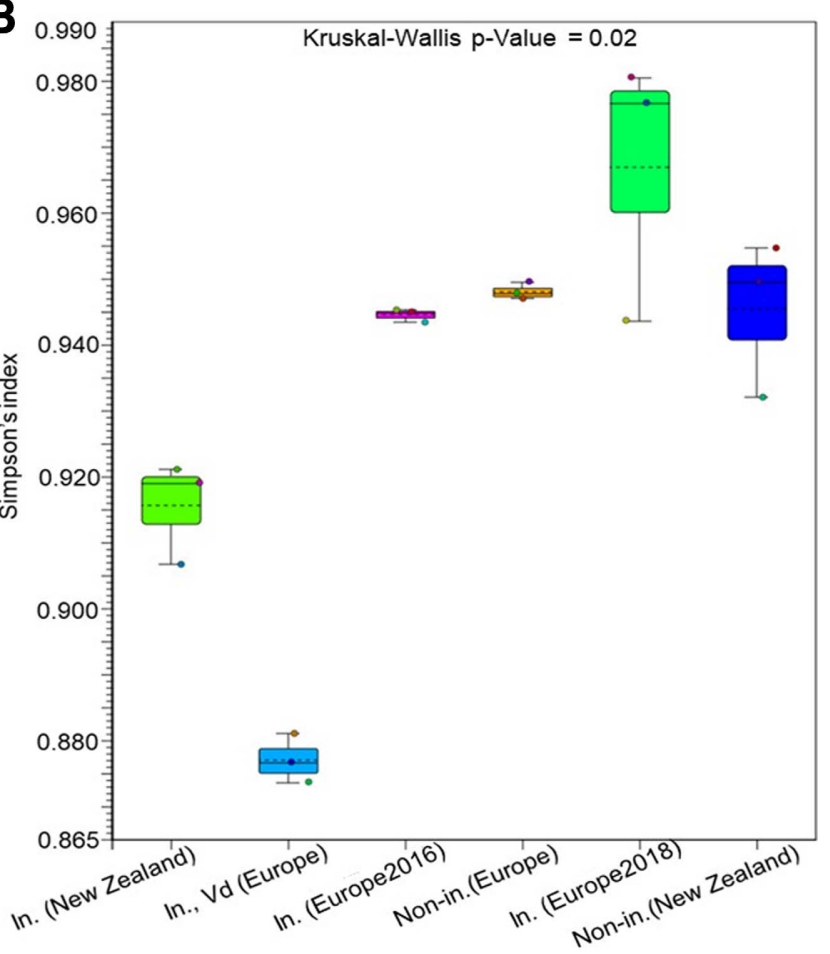

Fig. 4. Bacterial species richness and diversity index from six spinach seed lot samples from Europe and New Zealand. Within-sample $\alpha$ diversity was identified by A, total number of species and B, Simpson's index. Box plots show medians (solid line) and means (dotted line) with box borders percentile $=25$ and Whiskers range factor $=1.5$. The Kruskal-Wallis $\mathrm{H}$ test was used for statistical comparison across seed samples. In. $=$ infested with Peronospora effusa and Verticillium dahliae, In. $\mathrm{Vd}=$ infested only with $V$. dahliae, and Non-In. = not infested with either pathogen. 
New Zealand samples were distinct from European samples (Figs. 1 and 2). Also, the abundance of genus Xanthomonas was noticeably high in infested seed lots from Europe. Both beneficial and plantpathogenic microbes can assemble into seeds which can be passed from parental population to offspring through seeds (Shade et al. 2017). Stenotrophomonas spp. positively interact with host plants and confer tolerance over stress and improve the overall plant growth (Ryan et al. 2009). Furthermore, Stenotrophomonas strains contribute to biogeochemical cycles, including nitrogen and sulfur cycles (Kumar et al. 2019). Other potential plant-growth-promoting bacterial species abundant in seed lots were H. zhanjiangensis, Curtobacterium sp., and Enterobacter sp., which can be crucial for germination and

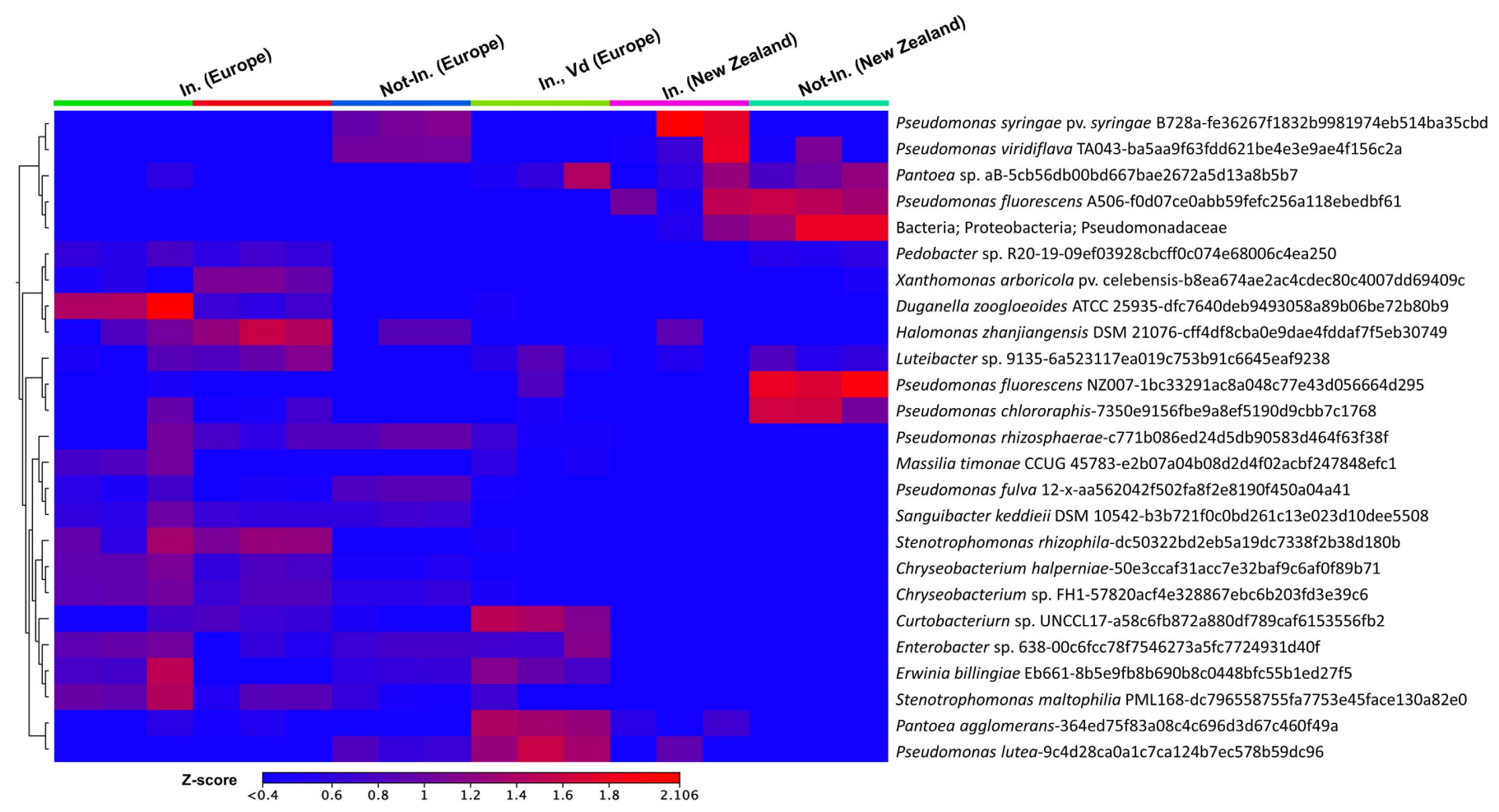

Fig. 5. Hierarchical clustering of the abundance of bacterial species in spinach seed lots from Europe and New Zealand. In. = infested with Peronospora effusa and Verticillium dahliae, In. Vd = infested only with $V$. dahliae, and Non-In. = not infested with either pathogen.

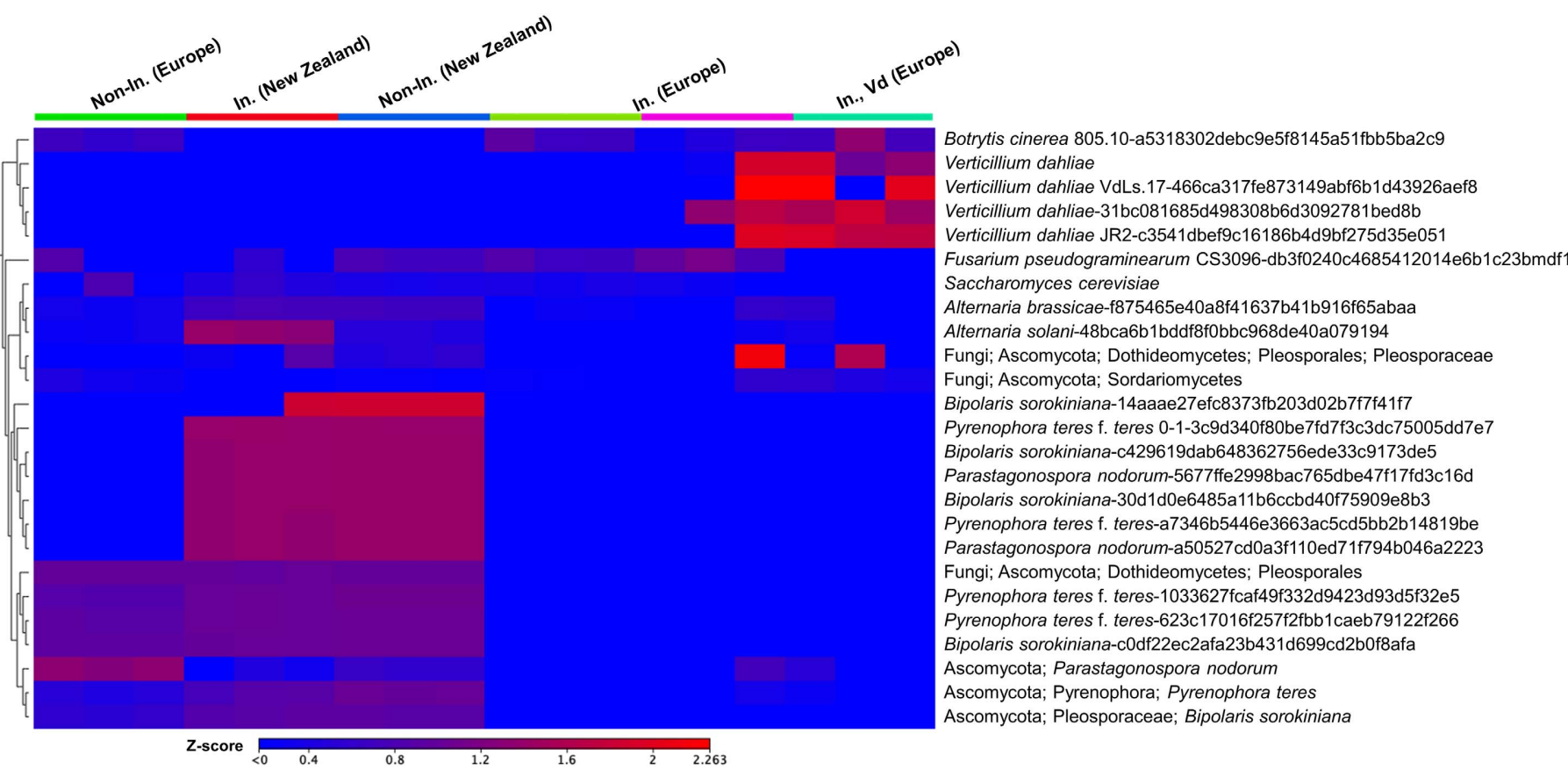

Fig. 6. Hierarchical clustering of abundance values in fungal community analyses of six spinach seed lots from Europe and New Zealand. In. $=$ infested with Peronospora effusa and Verticillium dahliae, In. Vd = infested only with V. dahliae, and Non-In. = not infested with either pathogen. 
seedling health (de Souza Vandenberghe et al. 2017; Wolfgang et al. 2020). In this study, we found higher abundance of Enterobacter sp. 638 in European seed samples relative to New Zealand samples. Enterobacter sp. 638 is a plant endophyte that has been well characterized for its role in plant growth promotion and drought resistance (Taghavi et al. 2010). Furthermore, the seedborne strain Enterobacter sp. modulates root morphology, creating a defense layer on the rhizoplace, thereby preventing infections from $F$. graminearum (Mousa et al. 2016).

From the differential abundance analysis, we observed that New Zealand seed lots (infested and noninfested) shared higher numbers of bacterial species than the European lots (Fig. 4). In total, 22 bacterial and 5 fungal species present in all seed lots were the commonly abundant microbiomes of the spinach seed lots we examined; however, further sampling of other spinach seed lots may reveal that some of these are not always present. Commonly abundant microbiomes present in seeds and seedlings are considered more reproducible than in mature plants (Tannenbaum et al. 2020; Toju et al. 2018). Seed microbiomes begin to colonize the seedlings soon after soil contact and influence seedling health significantly (Kandel et al. 2017; Trivedi et al. 2020). In the New Zealand samples, there was a higher abundance of Pseudomonas syringae pv. syringae and $P$. viridiflava identified in infested seed lots, while P. fluorescens A506 was in the noninfested sample. Isolates of $P$. syringae can infect spinach, leading to water-soaked, dark-brown spots in leaves (Koike et al. 2002). Beneficial seed microbiomes may mobilize during seed imbibition and germination and initiate positive influences on seedling health. Pantoea and Pseudomonas spp. were observed as core bacterial species in spinach seeds. In previous studies, the vital role of these bacterial species in plant growth promotion and suppressing of plant pathogens have been reported (Kandel et al. 2017; Links et al. 2014; Trivedi et al. 2020). The biocontrol and growthpromoting property of $P$. fluorescens A506 has been documented before (Lindow and Suslow 2003). The presence of $P$. fluorescens A506 in noninfested seed lot samples indicates the potential implication of this strain in seedling health and plant growth.

The abundance of the fungal family Pleosporaceae and the genus Alternaria was considerably higher in New Zealand samples but numbers of Sclerotiniaceae and Botrytis were higher in European samples (Fig. 2). Interestingly, the abundance of genus Verticillium was exceptionally high in the seed lots only infested with $V$. dahliae. Perhaps, V. dahliae proliferated considerably in the

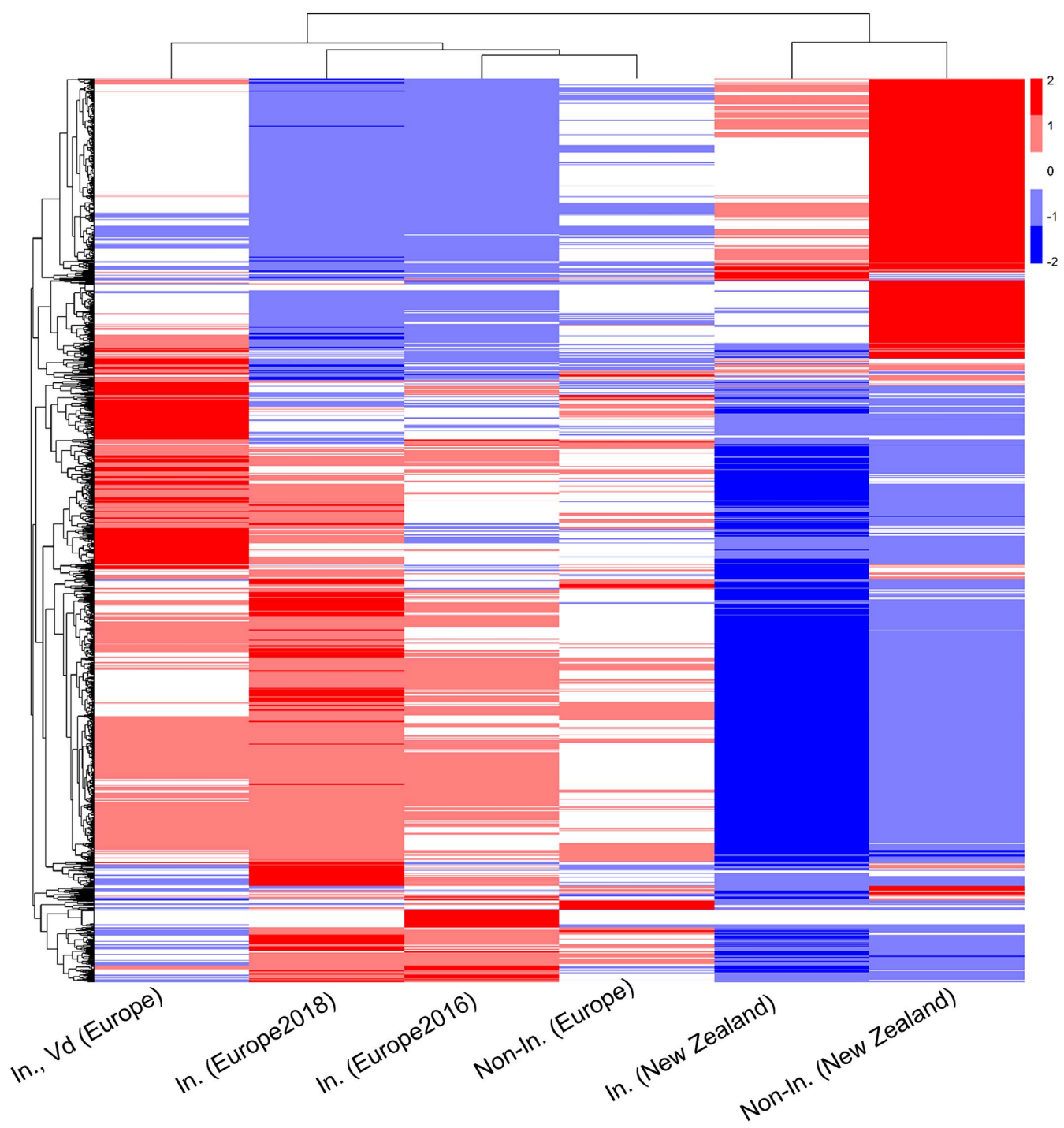

Fig. 7. Hierarchical clustering of gene ontology terms and abundance values obtained from sampling of six spinach seed lots from Europe and New Zealand. Dark red and blue colors indicate high abundance and mild to light colors indicate smaller abundance. In. $=$ infested with Peronospora effusa and Verticillium dahliae, In. $\mathrm{Vd}=$ infested only with $V$. dahliae, and Non-In. = not infested with either pathogen. 
absence of Peronospora effusa because both organisms possibly shared the same colonization niches and resources in the seed. The hierarchical clustering of differential abundance values showed that $V$. dahliae was exclusively present in the Verticillium-infested seed lots in comparison with $V$. dahliae- and $P$. effusa-infested or noninfested seed lots. Notably, $V$. dahliae is present in soils where seed production occurs in northern Europe (Sapkota et al. 2016), is commonly present in spinach seed lots (Duressa et al. 2012; du Toit et al. 2005; Maruthachalam et al. 2013), and inoculum of $V$. dahliae carried on seed can infect subsequent lettuce crops that are grown in rotation with spinach (Short et al. 2015). Moreover, higher abundance of B. cinerea B05.10 was found in both $P$. effusa- and $V$. dahliae-infested and noninfested seed samples of European origin. B. cinerea is an important pathogen of many crops in the region, including strawberry, and spinach seeds may serve as a source of new genetic variation in this species (Rupp et al. 2017).

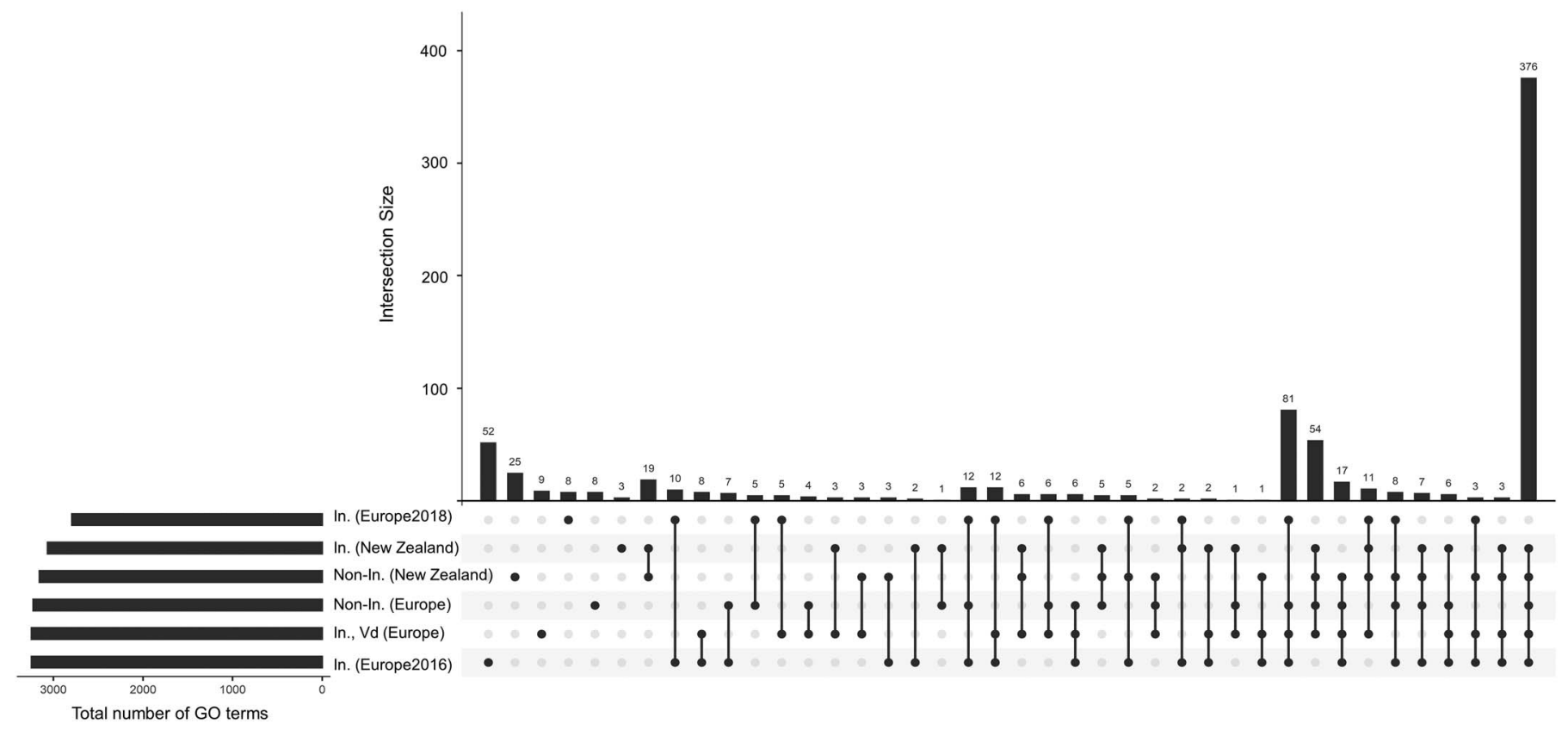

Fig. 8. UpSet plot of unique and intersected gene ontology (GO) terms among seed samples. Total GO terms in each sample were displayed through set size. Vertical bars represent the unique and intersections across seed samples listed below. In. = infested with Peronospora effusa and Verticillium dahliae, In. $\mathrm{Vd}=$ infested only with $V$. dahliae, and Non-In. = not infested with either pathogen.

A

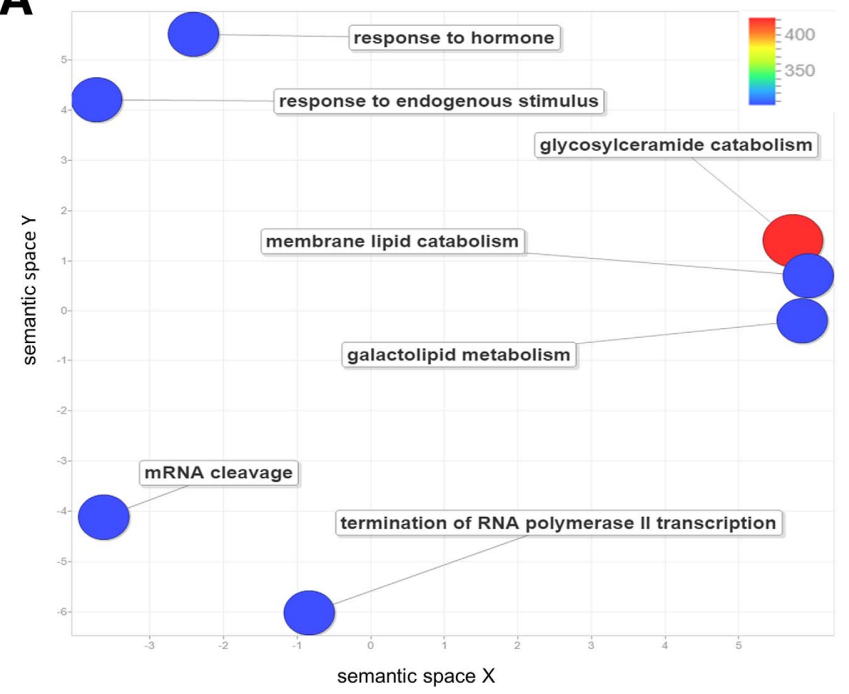

B

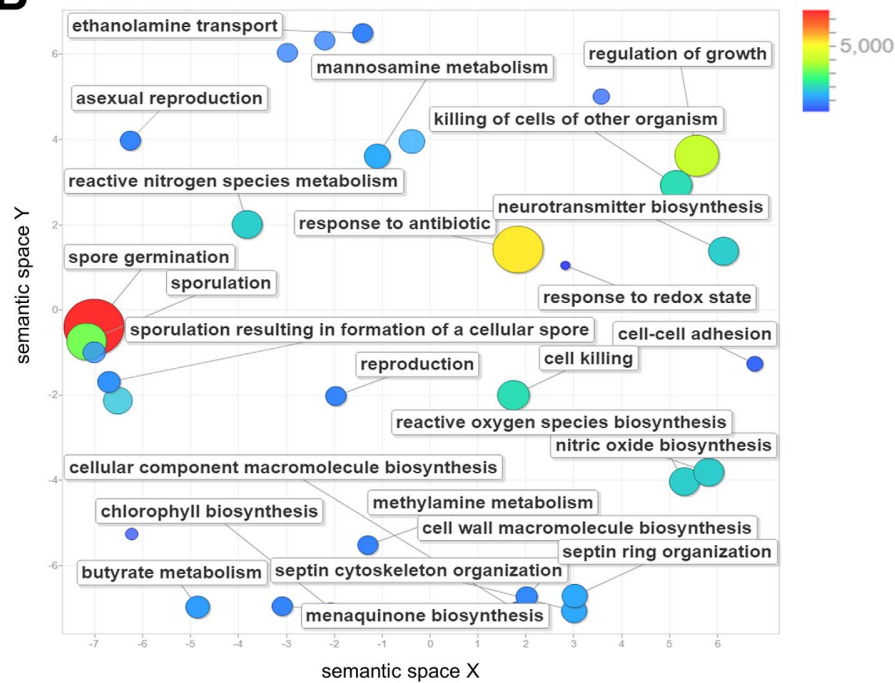

Fig. 9. Core gene ontology (GO) terms identified in New Zealand and European seed lots were summarized and visualized as a scatter plot using REVIGO. Summary of GO terms related to biological processes in spinach seed microbiomes of A, New Zealand seed lots, and B, European seed lots. GO terms are displayed by circles and are plotted according to semantic similarities to other GO terms (nearby circles are most closely related). Circle size indicates the combined abundance across seed samples, whereas color shows the proportional to the frequency of the GO term (red = higher and blue = lower). In. = infested with Peronospora effusa and Verticillium dahliae, In. Vd = infested only with V. dahliae, and Non-In. = not infested with either pathogen. 
Although the microbial populations from infected and noninfected (with $P$. effusa and $V$. dahliae) seeds were dissimilar in their abundance among different samples, technical limitations should be taken into consideration in the analysis of in silico data. Comparisons of the microbial population based on relative abundance could be technically biased (Lundberg et al. 2021). The reference database of whole fungal and bacterial genomes may not be entirely inclusive of the taxonomic diversity present, and the relative abundance of microbial taxa detected may be influenced by exceptionally low amounts of the DNA of certain taxa recovered in the DNA extraction steps. Nevertheless, the taxonomic diversity from ampliconbased taxonomic profiling using 16S and ITS rRNA genes and whole-genome databases were roughly comparable. Furthermore, previous studies suggested that shotgun metagenomics performs better than 16S rRNA-based profiling for detecting low-abundance microbial units (Franzosa et al. 2015; Han et al. 2020; Jovel et al. 2016). We also examined the functional profiling of prokaryotic genes in de novo assembled metagenomes. GO terms related to response to endogenous stimulus, hormone, and auxin were uniquely identified in metagenomes of New Zealand seed lots, among others. Because Pseudomonas syringae pv. syringae, $P$. viridiflava, and $P$. fluorescens were more abundant in these seed samples, genes responding to chemical signals of plant origin were perhaps crucial in these Pseudomonas strains to initiate pathogenic or mutualistic interactions with the host plant. In P. fluorescensinoculated Arabidopsis seedlings, auxin signaling was found responsible for increasing root and shoot biomass and lateral root formation (Ortiz-Castro et al. 2020). Conversely, auxin was considered to be a critical virulence factor for $P$. syringae strains (Kunkel and Harper 2018). GO terms related to response to antibiotic cell killing, response to antibiotic killing of cells of other organisms, killing of cells in other organisms involved in symbiotic interaction, and so on indicated that specific microbial processes exist in bacterial communities of European seed lots. These gene products may be vital for microbe-microbe and plant-microbe interactions.

$V$. dahliae is a highly damaging pathogen to several specialty crops grown in rotation with spinach in California, including lettuce and strawberry (Atallah et al. 2010). Interestingly, because the symptoms of Verticillium wilt do not develop before harvest of fresh spinach crops (Maruthachalam et al. 2013), V. dahliae does not impact spinach yield. Nevertheless, because $V$. dahliae carried on spinach seeds infects subsequent lettuce grown in the same soil (Short et al. 2015), efforts to reduce the pathogen on seed are advised. Peronospora effusa, on the other hand, when carried on seed, may impact spinach yields directly; thus, phytosanitary thresholds may be useful to reduce the number of oospores per seed that enter the production system (Choudhury et al. 2017).

The results of the current study do not indicate the viability of seedborne microorganisms identified based upon metagenomic analyses. However, seed health testing previously established the viability of fungi isolated from spinach seeds, including Stemphylium, Cladosporium, Fusarium, Verticillium, and Alternaria spp. (Olesen et al. 2011). Future studies will investigate the viability of additional bacterial and fungal taxa such as $B$. cinerea identified on spinach seed in this study, which may be damaging to strawberry. Additional studies that relate to the colonization of seed microbiomes in crop plants and the influence of seed and soil microbiomes on host defense or biocontrol will be useful to manage plant pathogens.

\section{ACKNOWLEDGMENTS}

We thank S. K. Shakya for functional analyses.

\section{LITERATURE CITED}

Atallah, Z. K., Maruthachalam, K., du Toit, L., Koike, S. T., Michael Davis, R., Klosterman, S. J., Hayes, R. J., and Subbarao, K. V. 2010. Population analyses of the vascular plant pathogen Verticillium dahliae detect recombination and transcontinental gene flow. Fungal Genet. Biol. 47: 416-422.

Barret, M., Guimbaud, J. F., Darrasse, A., and Jacques, M. A. 2016. Plant microbiota affects seed transmission of phytopathogenic microorganisms. Mol. Plant Pathol. 17:791-795.

Berg, G., and Raaijmakers, J. M. 2018. Saving seed microbiomes. ISME J. 12:1167-1170

Bergna, A., Cernava, T., Randler, M., Grosch, R., Zachow, C., and Berg, G. 2018. Tomato seeds preferably transmit plant beneficial endophytes. Phytobiomes J. 2:183-193.

Carroll, C., Carter, C., Goodhue, R., Lawell, C., and Subbarao, K. 2017. The economics of managing Verticillium wilt, an imported disease in California lettuce. Calif. Agric. 71:178-183.

Charney, N., and Record, S. 2012. vegetarian: Jost diversity measures for community data. Library (vegetarian), R version 4.0.3. https://rdrr.io/cran/ vegetarian/

Choudhury, R. A., Garrett, K. A., Klosterman, S. J., Subbarao, K. V., and McRoberts, N. 2017. A framework for optimizing phytosanitary thresholds in seed systems. Phytopathology 107:1219-1228.

Choudhury, R. A., Koike, S. T., Fox, A. D., Anchieta, A., Subbarao, K. V., Klosterman, S. J., and McRoberts, N. 2016. Season-long dynamics of spinach downy mildew determined by spore trapping and disease incidence. Phytopathology 106:1311-1318.

Condit, R., Pitman, N., Leigh, E. G., Chave, J., Terborgh, J., Foster, R. B., Nunez, P., Aguilar, S., Valencia, R., Villa, G., and Muller-Landau, H. C. 2002. Beta-diversity in tropical forest trees. Science 295:666-669.

de Souza Vandenberghe, L. P., Garcia, L. M. B., Rodrigues, C., Camara, M. C., de Melo Pereira, G. V., de Oliveira, J., and Soccol, C. R. 2017. Potential applications of plant probiotic microorganisms in agriculture and forestry. AIMS Microbiol. 3:629-648.

Duressa, D., Rauscher, G., Koike, S. T., Mou, B., Hayes, R. J., Maruthachalam, K., Subbarao, K. V., and Klosterman, S. J. 2012. A real-time PCR assay for detection and quantification of Verticillium dahliae in spinach seed. Phytopathology 102:443-451.

du Toit, L. J., Derie, M. L., and Hernandez-Perez, P. 2005. Verticillium wilt in spinach seed production. Plant Dis. 89:4-11.

Feng, C., Mansouri, S., Bluhm, B. H., du Toit, L. J., and Correll, J. C. 2014 Multiplex real-time PCR assays for detection of four seedborne spinach pathogens. J. Appl. Microbiol. 117:472-484.

Fitzpatrick, C. R., Salas-Gonzalez, I., Conway, J. M., Finkel, O. M., Gilbert, S., Russ, D., Teixeira, P. J. P. L., and Dangl, J. L. 2020. The plant microbiome: From ecology to reductionism and beyond. Annu. Rev. Microbiol. 74:81-100.

Foss, C. R., and Jones, L. J. 2000. Crop profile for spinach seed in Washington. Washington State University Extension. https://research. wsulibs.wsu.edu/xmlui/handle/2376/7079

Franzosa, E. A., Hsu, T., Sirota-Madi, A., Shafquat, A., Abu-Ali, G., Morgan, X. C., and Huttenhower, C. 2015. Sequencing and beyond: Integrating molecular 'omics' for microbial community profiling. Nat. Rev. Microbiol. 13:360-372.

Gene Ontology Consortium. 2004. The Gene Ontology (GO) database and informatics resource. Nucleic Acids Res. 32:D258-D261.

Han, D., Gao, P., Li, R., Tan, P., Xie, J., Zhang, R., and Li, J. 2020. Multicenter assessment of microbial community profiling using $16 \mathrm{~S}$ rRNA gene sequencing and shotgun metagenomic sequencing. J. Adv. Res. 26:111-121.

Hassani, M. A., Ozkurt, E., Seybold, H., Dagan, T., and Stukenbrock, E. H. 2019. Interactions and coadaptation in plant metaorganisms. Annu. Rev. Phytopathol. 57:483-503.

Hernandez-Perez, P., and du Toit, L. J. 2006. Seedborne Cladosporium variabile and Stemphylium botryosum in spinach. Plant Dis. 90:137-145.

Inaba, T., Takahashi, K., and Morinaka, T. 1983. Seed transmission of spinach downy mildew. Plant Dis. 67:1139-1141.

Jovel, J., Patterson, J., Wang, W., Hotte, N., O'Keefe, S., Mitchel, T., Perry, T., Kao, D., Mason, A. L., Madsen, K. L., and Wong, G. K. S. 2016. Characterization of the gut microbiome using 16S or shotgun metagenomics. Front. Microbiol. 7:459. 
Kabir, Z., Bhat, R. G., and Subbarao, K. 2004. Comparison of media for recovery of Verticillium dahliae from soil. Plant Dis. 88:49-55.

Kandel, S. L., Hulse-Kemp, A. M., Stoffel, K., Koike, S. T., Shi, A., Mou, B., Van Deynze, A., and Klosterman, S. J. 2020. Transcriptional analyses of differential cultivars during resistant and susceptible interactions with Peronospora effusa, the causal agent of spinach downy mildew. Sci. Rep. 10:6719.

Kandel, S. L., Joubert, P. M., and Doty, S. L. 2017. Bacterial endophyte colonization and distribution within plants. Microorganisms 5:77.

Kandel, S. L., Mou, B., Shishkoff, N., Shi, A., Subbarao, K. V., and Klosterman, S. J. 2019. Spinach downy mildew: Advances in our understanding of the disease cycle and prospects for disease management. Plant Dis. 103:791-803.

Klosterman, S. J., Atallah, Z. K., Vallad, G. E., and Subbarao, K. V. 2009. Diversity, pathogenicity, and management of Verticillium species. Annu. Rev. Phytopathol. 47:39-62.

Koike, S. T., Azad, H. R., and Cooksey, D. C. 2002. First report of bacterial leaf spot of spinach caused by a Pseudomonas syringae pathovar in California. Plant Dis. 86:921.

Koike, S. T., Cahn, M., Cantwell, M., Fennimore, S., Lestrange, M., Natwick, E., Smith, R. F., and Takele, E. 2011. Spinach production in California. Univ. Calif. Agric. Nat. Resour. Publ. 7212.

Kumar, A., Soni, R., Kanwar, S. S., and Pabbi, S. 2019. Stenotrophomonas: A versatile diazotrophic bacteria from the rhizospheric soils of Western Himalayas and development of its liquid biofertilizer formulation. Vegetos 32:103-109.

Kunjeti, S. G., Anchieta, A., Subbarao, K. V., Koike, S. T., and Klosterman, S. J. 2016. Plasmolysis and vital staining reveal viable oospores of Peronospora effusa in spinach seed lots. Plant Dis. 100:59-65.

Kunkel, B. N., and Harper, C. P. 2018. The roles of auxin during interactions between bacterial plant pathogens and their hosts. J. Exp. Bot. 69:245254.

Lex, A., Gehlenborg, N., Strobelt, H., Vuillemot, R., and Pfister, H. 2014. UpSet: Visualization of intersecting sets. IEEE Trans. Visualization Comput. Graphics 20:1983-1992.

Lindow, S. E., and Suslow, T. V. 2003. Temporal dynamics of the biocontrol agent Pseudomonas fluorescens strain A506 in flowers in inoculated pear trees. Phytopathology 93:727-737.

Links, M. G., Demeke, T., Grafenhan, T., Hill, J. E., Hemmingsen, S. M., and Dumonceaux, T. J. 2014. Simultaneous profiling of seed-associated bacteria and fungi reveals antagonistic interactions between microorganisms within a shared epiphytic microbiome on Triticum and Brassica seeds. New Phytol. 202:542-553.

Liu, B., Stein, L., Cochran, K., du Toit, L. J., Feng, C., and Correll, J. C. 2021. Three new fungal leaf spot diseases of spinach in the United States and the evaluation of fungicide efficacy for disease management. Plant Dis. 105:316-323.

Liu, B., Stein, L., Cochran, K., du Toit, L. J., Feng, C., Dhillon, B., and Correll, J. C. 2020. Characterization of leaf spot pathogens from several spinach production areas in the United States. Plant Dis. 104:19942004.

Liu, H., Carvalhais, L. C., Crawford, M., Singh, E., Dennis, P. G., Pieterse, C. M., and Schenk, P. M. 2017. Inner plant values: Diversity, colonization and benefits from endophytic bacteria. Front. Microbiol. 8: 2552.

Lundberg, D. S., Ayutthaya, P. P. N., Strauss, A., Shirsekar, G., Lo, W.-S., Lahaye, T., and Weigel, D. 2021. Host-associated microbe PCR (hamPCR) enables convenient measurement of both microbial load and community composition. eLife 10:e66186.

Maruthachalam, K., Klosterman, S. J., Anchieta, A., Mou, B., and Subbarao, K. V. 2013. Colonization of spinach by Verticillium dahliae and effects of pathogen localization on the efficacy of seed treatments. Phytopathology 103:268-280.

Mousa, W. K., Shearer, C., Limay-Rios, V., Ettinger, C. L., Eisen, J. A., and Raizada, M. N. 2016. Root-hair endophyte stacking in finger millet creates a physicochemical barrier to trap the fungal pathogen Fusarium graminearum. Nat. Microbiol. 1:16167.

Nelson, E. B. 2018. The seed microbiome: Origins, interactions, and impacts. Plant Soil 422:7-34.

Olesen, M. H., Carstensen, J. M., and Boelt, B. 2011. Multispectral imaging as a potential tool for seed health testing of spinach (Spinacia oleracea L.). Seed Sci. Technol. 39:140-150.
Olesen, M. H., Deleuran, L. C., Gislum, R., and Boelt, B. 2014. Preventing an increase in Verticillium wilt incidence in spinach seed production. Crop Prot. 66:107-113.

Ortiz-Castro, R., Campos-García, J., and López-Bucio, J. 2020. Pseudomonas putida and Pseudomonas fluorescens influence Arabidopsis root system architecture through an auxin response mediated by bioactive cyclodipeptides. J. Plant Growth Regul. 39:254-265.

Palmieri, D., Vitale, S., Lima, G., Di Pietro, A., and Turra, D. 2020. A bacterial endophyte exploits chemotropism of a fungal pathogen for plant colonization. Nat. Commun. 11:5264.

Pascale, A., Proietti, S., Pantelides, I. S., and Stringlis, I. A. 2020. Modulation of the root microbiome by plant molecules: The basis for targeted disease suppression and plant growth promotion. Front. Plant Sci. 10:1741.

R Core Team. 2020. The R Project for Statistical Computing. https://www.Rproject.org/

Rupp, S., Plesken, C., Rumsey, S., Dowling, M., Schnabel, G., Weber, R. W., and Hahn, M. 2017. Botrytis fragariae, a new species causing gray mold on strawberries, shows high frequencies of specific and efflux-based fungicide resistance. Appl. Environ. Microbiol. 83:e0269-17.

Ryan, R. P., Monchy, S., Cardinale, M., Taghavi, S., Crossman, L., Avison, M. B., Berg, G., Van Der Lelie, D., and Dow, J. M. 2009. The versatility and adaptation of bacteria from the genus Stenotrophomonas. Nat. Rev. Microbiol. 7:514-525.

Sapkota, R., Olesen, M. H., Deleuran, L. C., Boelt, B., and Nicolaisen, M. 2016. Effect of Verticillium dahliae soil inoculum levels on spinach seed infection. Plant Dis. 100:1564-1570.

Schloss, P. D., Westcott, S. L., Ryabin, T., Hall, J. R., Hartmann, M., Hollister, E. B., Lesniewski, R. A., Oakley, B. B., Parks, D. H., Robinson, C. J., and Sahl, J. W. 2009. Introducing mothur: Open-source, platformindependent, community-supported software for describing and comparing microbial communities. Appl. Environ. Microbiol. 75:7537-7541.

Shade, A., Jacques, M. A., and Barret, M. 2017. Ecological patterns of seed microbiome diversity, transmission, and assembly. Curr. Opin. Microbiol. 37:15-22.

Shahzad, R., Khan, A. L., Bilal, S., Asaf, S., and Lee, I. J. 2018. What is there in seeds? Vertically transmitted endophytic resources for sustainable improvement in plant growth. Front. Plant Sci. 9:24.

Short, D. P., Gurung, S., Koike, S. T., Klosterman, S. J., and Subbarao, K. V. 2015. Frequency of Verticillium species in commercial spinach fields and transmission of $V$. dahliae from spinach to subsequent lettuce crops. Phytopathology 105:80-90.

Singh, B. K., Trivedi, P., Egidi, E., Macdonald, C. A., and DelgadoBaquerizo, M. 2020. Crop microbiome and sustainable agriculture. Nat. Rev. Microbiol. 18:601-602.

Supek, F., Bosnjak, M., Skunca, N., and Smuc, T. 2011. REVIGO summarizes and visualizes long lists of gene ontology terms. PLoS One 6: e21800.

Taghavi, S., van der Lelie, D., Hoffman, A., Zhang, Y. B., Walla, M. D., Vangronsveld, J., Newman, L., and Monchy, S. 2010. Genome sequence of the plant growth promoting endophytic bacterium Enterobacter sp. 638. PLoS Genet. 6:e1000943.

Tannenbaum, I., Kaur, J., Mann, R., Sawbridge, T., Rodoni, B., and Spangenberg, G. 2020. Profiling the Lolium perenne microbiome: From seed to seed. Phytobiomes J. 4:281-289.

Toju, H., Peay, K. G., Yamamichi, M., Narisawa, K., Hiruma, K., Naito, K., Fukuda, S., Ushio, M., Nakaoka, S., Onoda, Y., and Yoshida, K. 2018. Core microbiomes for sustainable agroecosystems. Nat. Plants 4: 247-257.

Torres-Cortés, G., Bonneau, S., Bouchez, O., Genthon, C., Briand, M., Jacques, M. A., and Barret, M. 2018. Functional microbial features driving community assembly during seed germination and emergence. Front. Plant Sci. 9:902.

Trivedi, P., Leach, J. E., Tringe, S. G., Sa, T., and Singh, B. K. 2020. Plantmicrobiome interactions: From community assembly to plant health. Nat. Rev. Microbiol. 18:607-621.

Turner, T. R., James, E. K., and Poole, P. S. 2013. The plant microbiome. Genome Biol. 14:209.

UNITE Community. 2019. UNITE QIIME release for Fungi. https://plutof.ut. ee/\#/doi/10.15156/BIO/786334

USDA-FAS. 2020. FAS US Trade, imports-general, planting seeds (spinach). United States Department of Agriculture-Foreign Agricultural Service. https://apps.fas.usda.gov/gats/ExpressQuery1.aspx 
USDA-NASS. 2019. Agricultural Statistics 2019. USDA-NASS, Washington, DC. https://www.nass.usda.gov/

Wolfgang, A., Zachow, C., Muller, H., Grand, A., Temme, N., Tilcher, R., and Berg, G. 2020. Understanding the impact of cultivar, seed origin, and substrate on bacterial diversity of the sugar beet rhizosphere and suppression of soil-borne pathogens. Front. Plant Sci. $11: 1450$.

Zhong, C., Chen, C., Wang, L., and Ning, K. 2021. Integrating pan-genome with metagenome for microbial community profiling. Comput. Struct. Biotechnol. J. 19:1458-1466. 